\title{
Los trabajadores de Vía y Obras en los ferrocarriles de la Argentina a comienzos del siglo XX. Condiciones laborales, experiencias y vida cotidiana en el campamento
}

\author{
Track and Works laborers on the railways of Argentina at the \\ beginning of the 20th century. Work conditions, experiences and \\ daily life in the camp
}

\section{Florencia D' Uva*}

\begin{abstract}
Resumen: En la Argentina de comienzos del siglo XX los ferrocarriles ocupaban a un gran número de trabajadores de diversos oficios, calificaciones, edades y nacionalidades que se desempeñaban en los distintos departamentos en que se organizaban las compañías ferroviarias que prestaban servicio. Si bien durante los últimos años ha crecido la cantidad de estudios dedicados al universo laboral de los ferrocarriles, es más lo que se sabe sobre los trabajadores que se desempeñaban en las locomotoras o los talleres que sobre quienes se ganaban la vida trabajando en las estaciones, trenes, puestos de señales, barreras y cuadrillas de caminos. En este artículo el foco está puesto en los denominados trabajadores de "Vía y Obras", ocupados de la instalación, mantenimiento y reparación de rieles, puentes, señales y otras construcciones ferroviarias. Su objetivo es estudiar tanto las relaciones y condiciones laborales en las vías, como los reclamos, conflictos y redes de solidaridad forjadas por quienes integraban las cuadrillas. Se interesa puntualmente por desentrañar la dinámica del mundo del trabajo en los caminos ferroviarios prestando atención a las formas en que los trabajadores vivenciaron la experiencia de la explotación y la convivencia cotidiana en los campamentos, reconociéndose como parte de un colectivo común.
\end{abstract}

Palabras clave: peones; ferrocarriles; Argentina.

Profesora y Doctora en Historia por la Universidad de Buenos Aires. Becaria posdoctoral del CONICET con sede en el Instituto de Investigaciones en Estudios de Género de la Facultad de Filosofía y Letras (UBA). ORCID: https://orcid.org/0000-0001-8571-6945. Email: florenciaduva87@gmail.com. 
Abstract: In Argentina, at the beginning of the 20th century, railroads employed a large number of workers of various trades, qualifications, ages and nationalities who worked at the different departments in which the railway companies were organized. Although the number of studies dedicated to the railway work world has grown in recent years, more is known about the workers of the locomotives or workshops than about those who earned a living working in stations, trains, signal posts, barriers and road navies. In this article the focus is on the socalled "Track and Works" laborers, who were in charge of the installation, maintenance and repair of rails, bridges, signals and other railway constructions. Its objective is to study both the relations and the working conditions on the roads, as well as the claims, conflicts and solidarity networks forged by the men who were part of the crews. It is specifically interested in unraveling the dynamics of the work world on railways, paying attention to the ways in which workers lived the experience of exploitation and daily coexistence in the camps, recognizing themselves as part of a common collective.

Keywords: laborers; railroads; Argentina.

\section{Introducción}

A COMIENZOS DE LA DÉCADA DE 1930 la empresa de capitales británicos Ferrocarril Central Argentino publicó un folleto destinado al público viajero mediante el cual se buscaba dar a conocer el esfuerzo, la movilización de recursos y las hazañas organizativas implicadas en la circulación de los trenes. Para ello, "del enorme ejército de empleados", se seleccionaron aquellos que estaban en contacto más estrecho con los pasajeros para "personalizarlos" y proporcionar al público una idea sobre la compleja urdimbre del sistema ferroviario. Luego de describir las labores de algunos trabajadores de las estaciones, trenes y locomotoras tales como boleteros, guardas, maquinistas y camareros -, el folleto finalizaba con una breve reseña sobre el trabajo de los peones de cuadrilla:

Para el que viaja con frecuencia en el Ferrocarril el espectáculo de una cuadrilla de peones trabajando en la línea, entrevisto fugazmente al correr del tren, es una incidencia común que, por lo vulgar, ni siquiera despierta ya curiosidad.

Al avanzar el convoy, la cuadrilla se abre a los dos lados de la vía y sus hombres, apoyados en las herramientas de trabajo, suspenden breves instantes su ruda labor, para mirar, tal vez con nostalgia, los lujosos coches que pasan, llenos de pasajeros.

El tren desaparece a los pocos segundos en el horizonte, y la cuadrilla reanuda su labor anónima pero grande. El peón de cuadrilla, uno de los más modestos servidores del ferrocarril, tiene una destacada misión a su cargo: la conservación de las vías férreas. A su trabajo, ejecutado a rigor del sol en verano, bajo el intenso frío del invierno, se debe que los trenes puedan correr suavemente por las vías de acero, que los peones colocaron primero y cuidan perennemente después, reparando cualquier deficiencia, acudiendo 
al lugar donde la inundación, el desprendimiento de tierra o simplemente la acción devastadora del tiempo han afectado las vías, haciéndoles perder, de momento, su perfecta estabilidad [...]. ${ }^{1}$

Varias cuestiones se desprenden del relato sobre la labor de los peones. Por un lado, esta era presentada como invisible, ignorada o naturalizada por muchos de quienes viajaban en los ferrocarriles. A la vez, los hombres que junto con sus herramientas de trabajo conformaban la cuadrilla de peones aparecían como ajenos al lujo de los coches que circulaban por las vías $\mathrm{y}$, en contraste con los pasajeros que viajaban con las comodidades que, en mayor o menor medida, ofrecían los trenes, ejecutaban tareas rudas que requerían de un gran esfuerzo físico. Sujetos a las inclemencias del tiempo, su misión era la de mantener en condiciones las vías férreas ocupándose de su colocación, reparación y conservación. Sobre su trabajo, el folleto señalaba que una vez que las vías estaban tendidas y los trenes corriendo, era muy probable que nadie se detuviera a pensar en las semanas de intensa labor y esfuerzo sobrehumano que había costado aquella "doble cinta de acero". La narración invita a reflexionar sobre las representaciones existentes en torno a la labor de estos trabajadores, pero también plantea algunas preguntas sobre quiénes eran esos peones que conformaban las cuadrillas, cuáles eran sus tareas y sus condiciones de trabajo, las relaciones laborales en las que se encontraban inmersos, y cómo las experimentaron.

Distintos estudios historiográficos se abocaron a analizar a los trabajadores de los ferrocarriles en la Argentina y, en parte, ello se debe al rol que estos ocuparon al desempeñarse en una actividad central en la economía del país entre fines del siglo XIX y las primeras décadas del siguiente. Si bien en un comienzo las investigaciones se centraron en el análisis de las organizaciones sindicales ferroviarias e indagaron su estructura y funcionamiento, sus orientaciones político-ideológicas, su relación con las autoridades de las empresas y los hombres del Estado, ${ }^{2}$ con el tiempo se fueron sumando nuevas preguntas e inquietudes que dieron pie al surgimiento de otros estudios. Algunos reconstruyeron las luchas llevadas adelante por los trabajadores organizados y examinaron la participación de las mujeres en las protestas, otros indagaron sus instancias de formación y capacitación, sus espacios de sociabilidad y sus redes de solidaridad, contribuyendo al conocimiento de cada vez más aspectos del mundo laboral en los ferrocarriles. ${ }^{3}$ Sin embargo, mientras que

1 Ferrocarril Central Argentino. Siluetas, Buenos Aires, 1933.

2 GORDILLO, Mónica. La Fraternidad en el movimiento obrero: un modelo especial de relación (1916-1922). Buenos Aires: CEAL, 1988a; GORDILLO, Mónica. El movimiento obrero ferroviario desde el interior del país (1916-1922). Buenos Aires: CEAL, 1988b; HOROWITZ, Joel. Los trabajadores ferroviarios en la Argentina, 1920-1943. La formación de una elite obrera. Desarrollo Económico, v. 25, n. 99, p. 421-446, oct.-dec. 1985; SURIANO, Juan. Estado y conflicto social: el caso de la huelga de maquinistas ferroviarios de 1912. Boletín del Instituto de Historia Argentina y Americana, “Dr. E. Ravignani”, n. 4, p. 91-115, 1991.

3 AYUSO, María Luz. Red de escuelas técnicas de autogestión obrera. La Fraternidad, entre la política y la pedagogía (1887-1927). Rosario: Prohistoria, 2017; BADALONI, Laura. Huelga Ferroviaria de 1917. Violencia, complot maximalista y mujeres incendiarias. In: BONAUDO, Marta S. (dir.). Imaginarios y prácticas de un orden burgués. Rosario, 1850-1930. Instituciones, conflictos e identidades. De lo "nacional" a lo local, Tomo II. Rosario: Prohistoria, 2010. p. 95-116; D' UVA, Florencia. Ayuda mutua, solidaridad gremial y género entre los trabajadores ferroviarios. Argentina, 1912-1917. Boletín del Instituto de Historia Argentina y Americana 
buena parte de las investigaciones se centraron en los trabajadores que se desempeñaban en las locomotoras o los talleres, ${ }^{4}$ es menos lo que se sabe sobre quienes se ganaban la vida trabajando en las estaciones, trenes, puestos de señales, barreras y cuadrillas de caminos. Dispersos por todo el país, un gran número de trabajadores atendía las distintas labores de cada uno de los departamentos y servicios en que se organizaban las empresas ferrocarrileras, tanto aquellas en manos de capitales extranjeros como las administradas por dependencias del Estado.

En este artículo el foco está puesto en los denominados trabajadores de "Vía y Obras" de los ferrocarriles en la Argentina de comienzos del siglo XX. Su objetivo es estudiar tanto las relaciones y condiciones laborales en las vías, como los reclamos, conflictos y redes de solidaridad forjadas por quienes integraban las cuadrillas. Se interesa puntualmente por desentrañar la dinámica del mundo del trabajo en los caminos ferroviarios prestando atención a las formas en que los trabajadores vivieron la experiencia de la explotación y la convivencia cotidiana en los campamentos, reconociéndose como parte de un colectivo común. Para cumplir su objetivo este escrito se sirve de fuentes varias tales como documentación producida por diversas compañías ferroviarias, revistas semanales ilustradas de tirada nacional, periódicos sindicales, informes elaborados por funcionarios gubernamentales, y las libretas personales del peón e inmigrante italiano Geniali Giretti, entre otras. La primera parte del artículo se detiene en la organización del trabajo dentro del departamento de Vía y Obras, reconstruye las tareas desempeñadas por quienes conformaban las cuadrillas, así como las formas de reclutamiento de los peones. En la segunda parte, el análisis se centra en las condiciones laborales de los peones, deteniéndose en la duración de la jornada de trabajo y los salarios, y examina algunos de los reclamos y huelgas llevadas adelante por las cuadrillas. Por último, se explora la vida cotidiana en los campamentos buscando recuperar cómo los propios peones vivieron sus experiencias laborales, sus condiciones de vida y trabajo.

“Dr. Emilio Ravignani”, n. 51, p. 87-122, jul.-dic. 2019; D’ UVA Florencia; PALERMO, Silvana. Vida sindical y sociabilidades masculinas: los trabajadores ferroviarios en la Argentina de principios del siglo XX. Archivos de historia del movimiento obrero y la izquierda, n. 7, p. 37-58, sept. 2015; MONSERRAT, María Alejandra. Los trabajadores ferroviarios: sus luchas y organizaciones sindicales en el contexto de la Argentina gobernada por el radicalismo (1916-1930). Cuadernos del Ciesal, n. 10, p. 97-118, jul.-dic. 2011; PALERMO, Silvana A. ¿Trabajo masculino, protesta femenina? La participación de la mujer en la gran huelga ferroviaria de 1917. In: BRAVO, Maria Celia; GIL LOZANO, Fernanda; PITA, Valeria (dir.). Historias de luchas, resistencias y representaciones. Mujeres en la Argentina, siglos XIX y XX. Tucumán: EDUNT, 2007. p. 91-121; PALERMO, Silvana A. El derecho a mantener el hogar: las demandas obreras en la gran huelga ferroviaria desde una perspectiva de género. Argentina, 1917. In: ANDÚJAR, Andrea et al. Vivir con lo justo. Estudios de historia social del trabajo en perspectiva de género. Argentina, siglos XIX y XX. Rosario: Prohistoria, 2016. p. 81-101.

4 AYUSO, op. cit.; BARRANCOS, Dora. Organización obrera y formación laboral a principios de siglo: los maquinistas y trabajadores gráficos. Universidad Tecnológica Nacional, 1989; BADALONI, Laura. Ingenieros británicos, ferroviarios comunistas y organización del trabajo en los talleres del FCCA durante las primeras décadas del siglo veinte. Historia Industrial. Economía y Empresa, n. 63, p. 133-160, 2016; MIRAVALLES, Ana. Los talleres invisibles. Una historia de los Talleres Ferroviarios Bahía Blanca Noroeste. Bahía Blanca: Ferrowhite, 2013. 


\section{El trabajo de las cuadrillas de Vía y Obras}

Hacia comienzos del SIGLO $x x$ todas las empresas ferroviarias que funcionaban en Argentina tenían organizados sus servicios sobre la base departamental, sistema que en un principio habían implantado las compañías británicas y que luego se había ido difundiendo a otras empresas. Este sistema, que buscaba la eficiencia y optimización del tiempo, cruciales para cumplir con la puntualidad de los servicios, consistía en la división del trabajo entre distintos departamentos, cada uno a cargo de un jefe que a su vez organizaba y controlaba el trabajo por medio de superintendentes seccionales distribuidos estratégicamente en las zonas de influencia de la línea. Entre departamentos como Explotación, Comercial, Mecánica, Contaduría y Almacenes, se encontraba el de Vía y Obras, cuya misión principal era mantener en buen estado de conservación y funcionamiento las vías, señales, telégrafos, alcantarillas, puentes, edificios y otras instalaciones, debiendo asimismo ocuparse del estudio, proyecto y ejecución de obras relacionadas con la expansión o mejoramiento del servicio ferroviario.

En la mayoría de las compañías el departamento de Vía y Obras solía estar dividido en secciones - conservación, obras nuevas, servicios auxiliares, señales y comunicaciones, entre otras - que involucraban a un gran número de trabajadores con distintas funciones y atribuciones. ${ }^{5}$ En general, el personal se encontraba organizado en cuadrillas permanentes o volantes, siendo estas últimas las encargadas de ejecutar los trabajos extraordinarios que no podían efectuar las primeras. ${ }^{6}$ Cada cuadrilla, a cargo de un capataz, estaba conformada por obreros que ocupaban diversas jerarquías - había personal "de oficio", de "semi-oficio" y "sin oficio" - como los capataces, segundos capataces, peones, serenos, cuidadores de campamentos y cocineros, los cuales tenían a su cargo distintas tareas. ${ }^{7}$

El capataz a cargo de la cuadrilla daba las órdenes a los peones y era el responsable por las herramientas y útiles que les entregaba. Estos debían guardarse en el depósito fijado en las estaciones o en el paraje designado cerca de la cuadrilla. Sólo tenía permiso para hacer tareas de conservación y para cualquier trabajo nuevo debía tener autorización por escrito de un inspector del departamento. Diariamente los capataces debían examinar los puentes, alcantarillas y vías de sus secciones y hacer figurar en tinta los jornales correspondientes a los peones de su cuadrilla. Cada mes debían pasar al ingeniero de su sección la planilla con el número de días que habían trabajado los peones, el precio de los jornales, lo que

$5 \quad$ RONALD, Juan. El problema de los ferrocarriles argentinos. Buenos Aires, 1945. p. 45-48. En 1900, de un total de casi 45.000 empleados y obreros de ferrocarriles en la Argentina, un $40 \%$ pertenecía al departamento de Vía y Obras (MINISTERIO DE OBRAS PÚBLICAS. Estadística gráfica de los ferrocarriles en explotación, 1857-1935. Buenos Aires: Talleres Gráficos del Ministerio de Obras Públicas, 1937).

6 FERROCARRIL MIDLAND DE BUENOS AIRES. Reglamento Interno. Buenos Aires, 1911. p. 91.

7 Entre el personal "de oficio" podía haber carpinteros, electricistas, ajustadores, pintores, revisadores de señales, guarda hilos, soldadores y torneros; entre los de "semi-oficio" podían encontrarse cloaquistas, empedradores y jardineros; y aquellos clasificados como "sin oficio" comprendían distintos tipos de peones, serenos, limpiadores y cocineros, entre otros (RONALD, op. cit., p. 80-81). 
cada uno debía por comida, así como la lista de los materiales que habían sido cambiados o renovados. ${ }^{8} \mathrm{~A}$ diferencia de los capataces, que en general cobraban un sueldo mensual, los peones de cuadrilla cobraban por jornal trabajado y se les descontaba una parte por concepto de manutención, en la que se incluían las comidas y desayuno, lo que generó, como se verá más adelante, diversos reclamos y protestas.

Los inspectores de Vía y Obras eran los máximos responsables del buen estado de sus secciones en lo relativo a la conservación de la vía, puentes, alcantarillas, alambrados y edificios, así como de la competencia de capataces y peones, y el mantenimiento de las herramientas y depósitos de los materiales. Dependían del ingeniero de sección, a quien de forma diaria debían avisar el punto en donde se encontraban y una vez a la semana remitir un parte detallando el trabajo hecho, así como cualquier novedad habida. ${ }^{9}$ Los ingenieros, por su parte, eran los encargados de organizar el trabajo de las cuadrillas y supervisar el desempeño de los capataces. Para ello realizaban viajes de inspección en los que controlaban las tareas realizadas. ${ }^{10}$ Se podía empezar como peón de cuadrilla y con el tiempo llegar a ser capataz e incluso inspector. Tal había sido el caso de José Cinalli, quien entró a trabajar como peón en el Ferrocarril Central Argentino en 1889, en 1900 ascendió a capataz y para 1910 pasó a desempeñar el cargo de inspector de Vía y Obras en la misma empresa. ${ }^{11}$

El grueso de la cuadrilla lo conformaban peones que tenían a su cargo la labor de conservación de las vías férreas que era crucial para la seguridad y buen funcionamiento del servicio. Sobre la importancia de la labor de los peones de Vía y Obras, a fines de 1912 el semanario PBT había señalado que a pesar de que viajando en tren era muy común ver, a ambos lados de la vía, a unos hombres trabajando en la compostura de una línea vieja o en la colocación de otra nueva, pocas veces uno se ponía a pensar en lo grande de su obra. "Estamos tan acostumbrados a verlos encorvados hacia la tierra soportando los rigores del frío y del calor, que no les damos importancia alguna: los miramos como un complemento del paisaje que nos ofrece la divina naturaleza", afirmaba la crónica. ${ }^{12}$ En un sentido similar se expresó un cronista de la revista del Ferrocarril Central Argentino a principios de 1915, cuando al recordar la labor de los peones señaló que, dirigidos por expertos inspectores y capataces, eran ellos quienes prestaban el mayor servicio de seguridad, al proteger los caminos revisando las juntas de los rieles, buscando los puntos débiles, las tuercas flojas, librando la vía de los efectos de las inundaciones, vigilando y corrigiendo la nivelación de los terraplenes, dando la

8 F.C.C.B.A. Reglamento General para el uso y gobierno de los empleados de la empresa solamente. Buenos Aires, 1908, p. 64.

9 F.C.C.B.A. Reglamento General para el uso y gobierno de los empleados de la empresa solamente. Buenos Aires, 1908, p. 58; FERROCARRIL MIDLAND DE BUENOS AIRES. Reglamento Interno, Buenos Aires, 1911, p. 88; FERROCARRIL CENTRAL DE CÓRDOBA. Reglamento general para el uso y gobierno de los empleados de la empresa solamente. Buenos Aires, 1915, p. 123-124.

10 FERROCARRILES DEL ESTADO. Legajo Personal, Juan E. Pereyra. Archivo General del Ferrocarril, Buenos Aires-Argentina. Fondo Recursos Humanos Ferroviarios.

11 Señor José Cinalli. Revista Mensual del F.C.C.A., Buenos Aires, p. 789, oct. 1915.

12 El obrero del riel. PBT, Buenos Aires, 21 dic. 1912. 
pendiente o dobladura necesaria a los rieles en las curvas, cuidando la conservación de las alcantarillas y restaurando los puentes, entre otras tareas posibles. ${ }^{13}$

Durante los trabajos, los peones debían tomar ciertos recaudos tales como colocar las señales de precaución en las vías, procurar no obstaculizar la marcha de los trenes, o cuidar que la tierra retirada al realizar un arreglo fuera correctamente distribuida fuera de las vías. Sus tareas implicaban reparar rieles y líneas telegráficas cuando notaran hilos cortados o sueltos, postes rotos u otro inconveniente, comunicando enseguida al jefe de estación más cercano tales desperfectos y los trabajos hechos para remediarlos. ${ }^{14}$ También, les correspondía hacer salir a los animales que se encontraran sobre las vías y enterrar a aquellos muertos, cortar el pasto sobre la vía, los costados de los terraplenes y el que cubriera las conexiones de señalización, cerrar las tranqueras de los pasos a nivel particulares y recoger los objetos caídos de los trenes. ${ }^{15}$ En casos de accidentes, las cuadrillas debían prestar su auxilio para realizar las tareas que fueran necesarias para normalizar las vías.

No pocos peones combinaban el trabajo en las cuadrillas - que, en el caso de las cuadrillas volantes, era un empleo temporal - con otras actividades y trabajos generalmente vinculados con la cosecha. En ambos casos, habitualmente, eran agencias particulares de colocaciones las que proveían de peones a las faenas agrícolas y las empresas de ferrocarriles. Según algunos relevamientos realizados por el Departamento Nacional del Trabajo, ${ }^{16}$ estas agencias cobraban por anticipado una comisión de alrededor de \$2 al colocado - un valor apenas mayor a lo que se les pagaba en promedio por un día de trabajo -, siendo en los meses de noviembre a marzo que aumentaba el pedido de peones, tanto para el agro como para los ferrocarriles. ${ }^{17} \mathrm{Al}$ respecto, una nota publicada en junio de 1904 en El Ferrocarril, periódico de la Confederación de Ferrocarrileros - gremio surgido a mediados de 1902 para nuclear a señaleros, cambistas, guardas y peones - denunció que las agencias de colocación engañaban a los obreros de los centros poblados, enviándolos a regiones lejanas en las que se encontraban desamparados y sin dinero suficiente para volver a la ciudad. Según informó, los peones reclutados encontraban un trabajo de pocos días porque las empresas, capataces, o contratistas, en arreglo con las agencias, los echaban

13 Guarda-vías y peones de cuadrilla. Revista Mensual del F.C.C.A., Buenos Aires, p. 71, ene. 1915.

14 FERROCARRIL CENTRAL DE CÓRDOBA. Reglamento del Telégrafo para Dirección y uso exclusivo de los Empleados de la Empresa. A regir desde el $1^{\circ}$ de febrero de 1915, p. 36; FERROCARRIL DEL SUD. Reglamento para el uso de los Superintendentes de Telégrafo y Señales, 1919, p. 32.

15 FERROCARRIL MIDLAND DE BUENOS AIRES. Reglamento Interno. Buenos Aires, 1911, p. 90.

16 Creado en 1907, a través de un elenco de funcionarios y profesionales especializados, el Departamento Nacional del Trabajo llevó a cabo detallados estudios, estadísticas e inspecciones que tenían como fin conocer y regular la realidad del mundo del Trabajo en la Argentina de principios de siglo. Para más información sobre esta agencia estatal, ver: LOBATO, Mirta Z.; SURIANO, Juan (comp.). La sociedad del trabajo. Las instituciones laborales en la Argentina (1900-1955). Buenos Aires: Edhasa, 2013; SOPRANO, Germán. El Departamento Nacional del Trabajo y su Proyecto de Regulación Estatal de las Relaciones Capital-Trabajo en Argentina, 1907-1943. In: PANETTIERI, José (comp.). Argentina: trabajadores entre dos guerras. Buenos Aires: Eudeba, 2000. p. 31-53.

17 BOLETÍN DEL DEPARTAMENTO NACIONAL DEL TRABAJO (en adelante BDNT) BDNT n. 19, 1911, p. 780; BDNT n. 22, 1913, p. 416; n. 25, 1910, p. 825. 
rápidamente y se "repartían" con el agenciero el importe de la comisión cobrada a los recién llegados. ${ }^{18}$

Durante 1912 las agencias habían colocado alrededor de 75.000 peones para trabajo ferroviario, sin embargo, desde agosto de 1913, con la creación de un Registro Nacional de Colocaciones a cargo del citado Departamento, y el cual no cobraba comisiones a obreros ni a patrones, disminuyó considerablemente la cantidad de peones ferroviarios colocados por las agencias particulares, que en 1916 fueron menos de 4000.19 Mediante la creación del Registro, funcionarios del Estado buscaron desmontar los procedimientos irregulares de los agentes, quienes, ante la falta de vigilancia y control, recurrían a distintas artimañas para multiplicar sus ingresos en perjuicio de los trabajadores, como era la práctica de la rotación del personal, denunciada por los propios obreros. De todos modos, según el mismo Departamento informaba, hacia 1916 las empresas ferroviarias habían disminuido sensiblemente la cantidad de colocaciones debido a la menor actividad en la reparación de las vías y en la construcción de nuevos ramales, perjudicando así a numerosos obreros. Según se especificaba, desde el estallido de la guerra europea en 1914, las demandas patronales habían comenzado a mermar hasta llegar a solicitar sólo a los hombres imprescindiblemente necesarios. ${ }^{20}$

Sobre la inestabilidad del trabajo de los peones, al describir a comienzos del siglo XX la situación de los hombres de las cuadrillas de Vía y Obras del Ferrocarril Provincial de Santa Fe, el abogado y médico catalán Juan Bialet Massé afirmó que en muchos tramos las vías se encontraban en mal estado y que ello se debía a que no había peones ya que estos se iban a las cosechas, donde ganaban buenos jornales mientras que las cuadrillas brillaban por su "raquitismo" o ausencia. ${ }^{21} \mathrm{Al}$ comentar el caso de los peones del Ferrocarril Pacífico, señaló que estos no se adherían, que eran meramente ambulantes y que si el jornal fuera más alto podría haber peones fijos. ${ }^{22}$ Probablemente, su movilidad de los espacios laborales también afectaba el establecimiento de relaciones familiares. En este sentido, en una entrevista realizada en 1970 por el historiador Luis Alberto Romero, el trabajador y dirigente sindical ferroviario Antonio Di Santo, que había entrado a trabajar al ferrocarril en 1936, contó que los

18 Las famosas cuadrillas. El Ferrocarril, Buenos Aires, p. 1, 15 jun. 1904.

19 BDNT n. 25, 1913, p. 1105; BDNT n. 36, 1918, p. 48; Registro Nacional de Colocaciones. Caras y Caretas, Buenos Aires, 14 ago. 1915.

20 BDNT n. 36, 1918, p. 246. El estallido de la Gran Guerra europea en 1914, sumado a la recesión económica comenzada en 1913, implicó la detención de la construcción de ferrocarriles, no sólo debido a la reducción de la afluencia de capital extranjero, sino también a la contracción de la demanda exterior de productos nacionales, lo que trajo aparejado una disminución de las importaciones y por lo tanto del volumen que los ferrocarriles transportaban. Efectivamente, entre 1914 y 1918 el crecimiento de la red fue mínimo - no superando los 200 kilómetros -, ritmo que se prolongaría durante los cuatro años siguientes al fin de la contienda.

21 BIALET MASSÉ, Juan. Informe sobre el estado de las clases obreras en el interior de la República. Tomo II. Buenos Aires: A. Grau, 1904. p. 127. Juan Bialet Massé fue un médico y abogado catalán que desarrolló la mayor parte de su carrera profesional en la Argentina. Durante la presidencia de Julio A. Roca, el entonces ministro del Interior Joaquín V. González le encomendó la elaboración de un informe sobre las condiciones de trabajo en el interior del país, con el propósito de que sirviera como base para una futura legislación obrera. Con el tiempo, el informe publicado en 1904 se convertiría en una de sus piezas mas destacadas. Se ha escrito mucho sobre esta obra, abordándola en toda su riqueza y desde distintas perspectivas. Al respecto, consultar el dossier: Bialet Massé cien años después. Entrepasados, n. 26, 2004.

BIALET MASSÉ, op. cit., tomo III, p. 352. 
peones eran hombres muy rudos y fuertes y que él, que había entablado amistad con muchos de ellos, nunca había conocido a alguno que hubiera contraído enlace. ${ }^{23}$

Evidentemente, muchos peones no estaban atados a ninguna labor específica y la posibilidad de abandonar su trabajo atentaba contra su proletarización y contra cualquier intento de disciplinarlos. A su vez, la temporalidad e inestabilidad de su trabajo parece haber operado en detrimento de su sindicalización. Sobre este tema, a comienzos de 1922, una nota publicada en el periódico de la Federación Obrera Ferrocarrilera (FOF) -sindicato fundado una década antes para nuclear al personal de Tráfico, Talleres y Vía y Obras- afirmaba que la mayoría de los peones no formaba parte de la organización gremial, y que cuando lo hacían, no acudían a las asambleas ni cotizaban regularmente. ${ }^{24}$ En el mismo sentido se expresó un peón del Ferrocarril Sud a fines de ese año al lamentarse por el grueso de los obreros de Vía y Obras de las diversas empresas, quienes todavía se mostraban indiferentes al sindicato, posibilitando procederes abusivos por parte de las compañías, como eran las rebajas de salario. ${ }^{25}$ Debido a ello, en alguna oportunidad las secciones de la FOF habían propuesto establecer una cuota reducida para facilitar el ingreso a la organización de los peones de cuadrilla, lo que, a juzgar por noticias posteriores, parece no haber dado demasiados resultados. ${ }^{26}$

\section{Condiciones de trabajo en las vías}

DISTINTAS EVIDENCIAS COINCIDEN en señalar las duras condiciones laborales que imperaban entre las cuadrillas encargadas de la construcción y mantenimiento de obras y caminos ferroviarios. En su informe publicado en 1904, Bialet Massé había apuntado que las jornadas de los peones solían prolongarse de sol a sol y que en algunos casos también se trabajaba los domingos, como sucedía con los peones del Ferrocarril Santa Fe quienes sólo cortaban el trabajo para tomar mate y comer, y en caso de ser necesario debían trabajar los domingos, cobrando el salario ordinario. ${ }^{27}$ En efecto, según los reglamentos internos de distintas compañías, los peones debían salir de sus casillas a la salida del sol y regresar a éstas a la puesta del sol, pudiendo ser requerido su trabajo los días domingos y feriados. ${ }^{28}$ Según informó hacia fines de 1906 un peón del Ferrocarril Sud a los dirigentes de la Confederación de Ferrocarrileros, el sol era para los obreros de las cuadrillas "una maldición", pues "cuanto más antes se levante

23 Entrevista a Antonio Di Santo por Luis Alberto Romero, 18 dic. 1970. Proyecto de Historia Oral del Instituto Torcuato Di Tella.

24 A los peones de cuadrilla. El Obrero Ferroviario, Buenos Aires, p. 2, 16 mar. 1922.

25 Dos palabras a los trabajadores de Vía y Obras. La Confraternidad, Buenos Aires, p. 2, dic. 1922.

26 Vías y Obras. El Obrero Ferroviario, Buenos Aires, p. 4, mar. 1917.

27 BIALET MASSÉ, op. cit., tomo II, p. 124-125.

28 F.C.C.B.A. Reglamento General para el uso y gobierno de los empleados de la empresa solamente. Buenos Aires, 1908, p. 59; FERROCARRIL MIDLAND DE BUENOS AIRES. Reglamento Interno. Buenos Aires, 1911, p. 89; FERROCARRIL CENTRAL DE CÓRDOBA. Reglamento general para el uso y gobierno de los empleados de la empresa solamente. Buenos Aires, 1915, p. 124-125. 
o más tarde se retire, tanto más hemos de trabajar". ${ }^{29}$ De este modo, denunciaba, durante el verano trabajaban 12 horas diarias bajo la mirada continua del capataz quien solo dejaba descansar un poco a sus preferidos, grupo compuesto generalmente por sus paisanos, parientes y los que gastaban dinero en su boliche, bebiendo vino y caña que el capataz vendía por su cuenta.

Sobre el lugar que ocupaban los peones en la estructura ferroviaria, una nota publicada en El Ferrocarril de marzo de 1906 aseguraba que el peón de cuadrilla constituía "la base de esa montaña de oro que forma el capital de las empresas ferrocarrileras" y que, ocupando el último peldaño en la escalera de las jerarquías, debía soportar el desprecio de la colectividad y la soberbia de los "pequeños superiores", es decir, los capataces. ${ }^{30}$ Sobre su rutina laboral, informó que los peones iniciaban su trabajo al romper el día y que en invierno debían aguantar el aire cortante de las mañanas frías envueltos en ropas que no siempre alcanzaban a cubrirlos debidamente. Mal pagos y mal alimentados, durante el largo día debían resistir las fatigas de una labor pesada para volver extenuados a descansar hasta que saliera nuevamente el sol. Al respecto, transcurridos casi setenta años, el ex ferroviario y dirigente sindical Antonio Di Santo, recordó en una entrevista que los peones de Vía y Obras constituían el nivel más bajo del trabajo ferroviario, "ajustados a un régimen de trabajo muy deprimente", con largas jornadas y salarios bajísimos. Contó que nunca había conocido a alguno que hubiera tenido una buena camisa, ni corbata, "ni siquiera un par de zapatos". ${ }^{31}$

A decir verdad, los trabajadores que cobraban los salarios más bajos en relación al salario promedio del personal de otros departamentos eran aquellos de Vía y Obras. Dentro de estos, además de las diferencias existentes entre las distintas empresas, podían existir diferencias según se tratara de capataces de cuadrilla, peones con oficio o semi-oficio, y peones sin calificación. Además, según los datos que la administración del ferrocarril de capitales británicos Buenos Aires al Pacífico proporcionó a Bialet Massé y que fueron publicados en su informe, los salarios de capataces y peones podían variar entre distintos tipos de cuadrillas y entre las distintas secciones de la línea, no teniendo un precio uniforme ni aun en el mismo ramal. Así, el salario de un capataz podía ser de entre $\$ 2.20$ a $\$ 3$ por día, el de un artesano oscilaba entre los $\$ 2.80$ y $\$ 4$ diarios y el de un peón no calificado entre $\$ 1.30$ y $\$ 2.40$ por día, de los que se descontaban entre 50 y 70 centavos para la comida. Por su parte el salario de un inspector de Vía y Obras variaba entre los $\$ 120$ y $\$ 175$ mensuales. ${ }^{32}$

29 Peones de vías y obras. El Ferrocarril, Buenos Aires, p. 4, 1 nov. 1906. Varios peones parecen haber sido conscientes de lo esforzado de sus tareas. Tal fue el caso de Luis Aldaz quien en una carta a su esposa que había quedado en España, le ordenaba no malgastar el dinero enviado "porque este es el producto de mi sudor, de mi trabajo sacrificado que empieza a las 4 de la madrugada y termina cuando se pone el sol [...] que me mantiene moviéndome de una a otra parte, cambiando durmientes en las vías" (citado en BJERG, María. Lazos Rotos: la inmigración, el matrimonio y las emociones en la Argentina entre los siglos XIX y XX. Bernal: Universidad Nacional de Quilmes, 2019. p. 68).

30 El peón de cuadrilla. El Ferrocarril, Buenos Aires, p. 2, 1 mar. 1906.

31 Entrevista a Antonio Di Santo por Luis Alberto Romero, 18 dic. 1970, Proyecto de Historia Oral del Instituto Torcuato Di Tella.

32 BIALET MASSÉ, op. cit., tomo III, p. 349-351. Estos valores eran semejantes a los que el reformista liberal Juan Alsina registró en su informe de 1905, sobre las condiciones de vida obrera en el país, para los trabajadores 
En general el sueldo de los peones era por jornal y el de los capataces era mensual, lo que reflejaba y reforzaba las jerarquías existentes, ya que un salario mensual permitía mayor estabilidad y previsibilidad económica, mientras que el pago por jornal implicaba mayor incertidumbre y variaciones en el salario percibido. Tal fue el caso de Juan Carlos Pallanza, quien entró a trabajar como peón de Vía y Obras en el ferrocarril de administración estatal Central Norte en 1897, puesto en el que se desempeñó durante tres años con un salario de $\$ 1.40$ por día. Luego de un período sin actividad registrada, en 1903 reanudó su vínculo con la empresa, esta vez como capataz, con un salario mensual de $\$ 60$ que se mantuvo hasta 1910 cuando comenzó a cobrar $\$ 70$ por mes. Durante 1911 y 1912 su salario mensual fue de $\$ 120$ y en 1913 fue de $\$ 100$ y $\$ 80$ en distintos tramos y ramales de la línea. ${ }^{33}$ Según el periódico de la FOF, El Obrero Ferroviario, por ese entonces un peón de una empresa de capitales franceses podía cobrar $\$ 80$ por mes. ${ }^{34}$ Mientras tanto, un maquinista percibía un salario mensual promedio de $\$ 210$, un foguista $\$ 110$, un guarda tren podía ganar alrededor de $\$ 90$ mensuales y un trabajador calificado de los talleres $\$ 120$ por mes o más. ${ }^{35}$

En algunas empresas y regiones, la remuneración de los peones podía ser considerablemente más baja. A mediados de 1912, según informó un peón que se encontraba trabajando en la provincia patagónica de Neuquén, levantando terraplenes para la prolongación de la vía férrea a Chile, y cobrando a destajo, el salario no alcanzaba los $\$ 50$ mensuales, y a veces, "en meses del mal tiempo" no llegaba siquiera a $\$ 20 .{ }^{36}$ Un año más tarde, al agudizarse la crisis económica y con ella las medidas de economía de las empresas ferroviarias, el periódico gremial denunció que en el Ferrocarril Oeste los sueldos de distintos trabajadores habían sido reducidos y que los de los peones de Vía y Obras habían sido rebajados en algunos casos de $\$ 2.40$ a $\$ 2$ diarios y en otros de $\$ 2$ a $\$ 1.80$. Al respecto, la nota se preguntaba: ¿Un hombre, generalmente padre de familia -como son muchos peones, faroleros y cambistas- puede vivir con su mujer y sus hijos con los cincuenta pesos que le pagan las empresas ferroviarias?", para enseguida advertir que las huelgas y demás trastornos que pudieran producirse serían el fruto de estas "economías tan descabelladas". ${ }^{37}$ Al respecto, unos meses más tarde el periódico del sindicato de maquinistas y foguistas La Fraternidad calculó en casi \$104 el costo de vida mensual de una familia obrera, incluyendo alquiler, gastos de almacén, alimentos y transporte. ${ }^{38}$

La referencia a las necesidades de la familia, a la vez que podía ser una estrategia de los trabajadores para legitimar sus reclamos y exponer la injusticia y arbitrariedades de las

agrícolas y azucareros en distintas provincias. ALSINA, Juan. El obrero en la República Argentina. Tomo I. Buenos Aires, 1905.

33 FERROCARRILES DEL ESTADO. Legajo Personal, Juan Carlos Pallanza. Archivo General del Ferrocarril, Buenos Aires-Argentina. Fondo Recursos Humanos Ferroviarios.

34 F.C. R. a P.B. El Obrero Ferroviario, Buenos Aires, p. 3, ene. 1913.

35 Escala de sueldos actuales. La Fraternidad, Buenos Aires, p. 5, 1 dic. 1911; C. General de Ferrocarriles de la P. de Buenos Aires. El Obrero Ferroviario, Buenos Aires, p. 3, feb. 1913.

36 Ecos del desierto. La Acción Obrera, Buenos Aires, p. 2, 6 jul. 1912.

37 ¡Cómo se hacen las economías! El Obrero Ferroviario, Buenos Aires, p. 1, mar. 1914.

38 La empresa, enemiga de la familia y la educación. La Fraternidad, Buenos Aires, p. 2, 1 nov. 1914. 
compañías, invita a pensar en las personas que se sostenían, o pretendían hacerlo, a partir de un salario. Evidentemente, contar con un sueldo no garantizaba la subsistencia obrera y, menos aun, la satisfacción de las necesidades de todo un grupo familiar. Esta situación se agravó en 1914 al estallar la guerra en Europa que, sumada a los efectos de la crisis económica, repercutió entre los trabajadores ferroviarios con prorrateos, suspensiones, despidos y rebajas de salarios. ${ }^{39}$ Los bajos salarios, combinados con un contexto económico adverso en el que aumentaba el costo de vida y se encarecían los artículos de primera necesidad, hacían estragos en la economía obrera. ${ }^{40}$ Por este motivo, el pedido de aumento de sueldos ocupó un lugar central en las demandas de los trabajadores ferroviarios, en especial durante las huelgas de 1917.

Desde comienzos del 1900, en distintas líneas ferroviarias, cuadrillas de peones llevaron a cabo diversas huelgas demandando aumentos de salario, reducción de la jornada laboral y mayor tiempo para el descanso. ${ }^{41}$ Algunas, inclusive, paralizaron el trabajo pidiendo mejor comida y consideración. Es que el tema del trato y de la alimentación, la cual estaba a cargo de los capataces de las cuadrillas, constituyó una fuente de conflicto en la relación desigual que existía entre peones y capataces. Al respecto, en sus estatutos aprobados en 1903, casi un año después de su conformación, la Confederación de Ferrocarrileros proponía como uno de sus objetivos que el personal de Vía y Obras fuera libre de proveerse de la comida y objetos de consumo "donde mejor le plazca y convenga" ${ }^{42}$ En 1904, una nota publicada en El Ferrocarril, periódico del gremio, denunciaba que los peones percibían un salario miserable del cual debían abonar una cuota diaria para la comida que estaban "condenados a tragar" y que la mayoría de las veces constituía una "verdadera tortura", debiendo asimismo trabajar desde el amanecer hasta el anochecer "bajo la mirada y la vigilancia de déspotas sin conciencia que tienen como única preocupación explotar a sus semejantes para imitar a sus patrones". ${ }^{43}$ Unos meses más tarde, al producirse una huelga entre el personal del Ferrocarril Sud, una de las demandas obreras especificaba que la empresa debía asegurar a los peones una comida "higiénica y abundante" evitando los abusos frecuentes cometidos contra los obreros de las cuadrillas por parte de los encargados de su dirección o administración. De lo contrario, se especificaba, debía darse la libertad a los peones de comer en donde a estos les resultara más conveniente. ${ }^{44}$ Tras prolongarse durante algunas semanas, los obreros dieron por terminada la protesta sin lograr que la empresa satisficiera sus reclamos.

39 Las economías de las empresas; Tafí Viejo. El Obrero Ferroviario, Buenos Aires, p. 2 y 4, sep. 1914; Las economías; En estos momentos; La situación ferroviaria. El Obrero Ferroviario, Buenos Aires, p. 1 y 2, oct. y nov. 1914; El prorrateo del trabajo. Nueva implantación. La Fraternidad, Buenos Aires, p. 3, 1 jun. 1914; El prorrateo del trabajo. La Fraternidad, Buenos Aires, p. 3, 15 ago. 1914.

40 BDNT n. 33, 1916, p. 226.

41 BUNGE, Alejandro E. Ferrocarriles argentinos. Contribución al estudio del patrimonio nacional. Buenos Aires, 1918. p. 342; FERNANDEZ, Manuel. La Unión Ferroviaria a través del tiempo. Buenos Aires, 1947. p. 77-80; Huelgas, El Ferrocarril, Buenos Aires, p. 4, 1 oct. 1906.

42 BDNT n. 4, 1908, p. 71.

43 Las famosas cuadrillas. El Ferrocarril, Buenos Aires, p. 1, 15 jun. 1904.

44 Antecedentes de la lucha. El Ferrocarril, Buenos Aires, p. 1, 30 ene. 1905. 
Tiempo más tarde, y a pesar de los reclamos de los trabajadores y sus gremios, el problema seguía vigente. En marzo de 1906 una nota aparecida en El Ferrocarril denunció lo mal que se pagaba a los peones apuntando especialmente contra la alimentación que recibían y por la cual se le descontaba casi un tercio del jornal diario. Según el autor del escrito, eso que se llamaba comida debía en su lugar llamarse "coima de capataces", quienes comparaban en las carnicerías "lo peor de la tumba" porque lo conseguían más barato y "con eso y fideos de la más oscura especie", hervido todo en una olla de lata, "sin más condimento que un puñado de sal", alimentaban a los peones mañana y noche. ${ }^{45} \mathrm{~A}$ fines de ese año, entrevistados por el periódico gremial, un grupo de peones del Ferrocarril Sud que se había declarado en huelga luego de que los capataces decidieran aumentar de 50 a 60 centavos diarios lo que se les cobraba por comida, denunció la mala calidad e insuficiencia de ésta, compuesta por mate por la mañana y una pequeña porción de puchero, fideos y galleta dura al mediodía y a la noche. "La sopa es inmunda, asquerosa, no se puede comer; la carne es insuficiente para mantener a un hombre durante tan largas horas de labor", sentenció uno de ellos. ${ }^{46}$ En esta misma línea, según la información que hacia fines de 1914 "dos ofendidos" enviaron a EI Obrero Ferroviario, los capataces se caracterizaban por ser abusivos y pretenciosos y no eran pocos los peones que, ante el temor, evitaban formular protesta alguna. Señalaban el caso puntual de Juan Guzmán, capataz del Ferrocarril Midland, quien trataba a sus subalternos con despotismo y les daba alimento insano. Para veintiocho peones disponía por día de un cuarto de yerba, medio kilo de azúcar, seis kilos y medio de carne - a veces en mal estado - y un poco de fideos que hacía hervir "en un tacho mugriento". ${ }^{47}$

Si bien tras las huelgas de 1917 los peones ganaron la libertad de comer o no de la olla, lo cierto es que, en la práctica, muchas veces esta disposición quedó sólo en el papel, tal como denunció a fines de 1920 un peón del Ferrocarril Sud. Este trabajador, de apellido Silva, llamaba a sus compañeros a organizarse y luchar por una mejor retribución y por concluir con la explotación de sus estómagos al abolir la olla, esa "mina de oro" de los capataces. En sus palabras, no debía quedar ni una sola olla en los campamentos y "el capataz que quiera comer que la sude como nosotros y así sabrán lo que es ganarse el sustento diario sin explotar a sus semejantes". ${ }^{48}$ Según una nota publicada dos años más tarde en el periódico gremial La Confraternidad, ${ }^{49}$ y escrita por un peón del Sud, debido a que el sueldo percibido por los capataces no era muy elevado, estos despojaban a los peones de su mísero jornal, obligándolos a pagar precios excesivos por una comida que el autor del escrito caracterizaba como "bazofia especial para cerdos". Explicaba que si bien la administración de la empresa había dispuesto que los peones podían comer donde les pareciera, la mayoría de los capataces

45 El peón de cuadrilla. El Ferrocarril, Buenos Aires, p. 2, 1 mar. 1906.

46 Peones de vías y obras. El Ferrocarril, Buenos Aires, p. 4, 1 nov. 1906.

47 Fiorito. El Obrero Ferroviario, Buenos Aires, p. 4, oct. y nov. 1914.

48 Generosidad burguesa. El Obrero Ferroviario, Buenos Aires, p. 3, 16 nov. 1920.

49 Órgano de prensa de La Confraternidad Ferroviaria, organización fundada en 1920 y conformada por los gremios ferroviarios La Fraternidad y Sindicato de Tráfico y Talleres, este último sucesor de la FOF. 
hacían caso omiso de dicha orden, obligando a los peones "pobres de espíritu" a comer lo que ellos le suministraban. ${ }^{50}$

Si bien con las huelgas en varias ocasiones los peones lograron su cometido, o al menos una leve mejora de su situación, estas no siempre daban el resultado esperado y los peones podían ser fácilmente reemplazados como sucedió a fines de 1912 cuando un grupo de peones del Ferrocarril Central Argentino fue despedido por pedir la jornada de 8 horas. ${ }^{51} \mathrm{~A}$ su vez, la poca sindicalización existente entre los peones pudo haber dificultado su acción conjunta y capacidad para sostener una medida de lucha. Tal parece haber sido el caso de los peones de Vía y Obras del Ferrocarril Sud pertenecientes a las secciones de Plaza Constitución, Talleres y Sola, quienes hacia fines de 1906 se declararon en huelga demandando la jornada de 8 horas, luego de que la empresa dispusiera que esta fuera de 9. Según informó EI Ferrocarril, estos trabajadores no estaban asociados a ninguna organización obrera y por ello no habían realizado ninguna gestión para impedir que se extendiera la jornada, limitándose a abandonar el trabajo a la espera de que la superioridad les pidiera explicaciones sobre los motivos de la huelga. ${ }^{52} \mathrm{Si}$ bien los dirigentes de la Confederación de Ferrocarrileros facilitaron un local gremial para las reuniones de los huelguistas y ofrecieron su intervención, lanzando un manifiesto en el que pedían la solidaridad de los demás obreros, la huelga fracasó. De acuerdo a la crónica publicada en el periódico del gremio, pasado el entusiasmo de los primeros momentos, los huelguistas comenzaron a desalentarse y, a ocho días de iniciado el conflicto, la mayoría decidió volver al trabajo. Según se afirmó, se esperaba que el fracaso sirviera de enseñanza a los peones de Vía y Obras quienes debían comprender "la imprescindible necesidad de asociarse y de formar una sólida organización", única herramienta posible para asegurar el éxito de las luchas futuras. ${ }^{53}$

La conflictividad entre los trabajadores del riel alcanzó su pico máximo en 1917, año en que se produjeron diversas huelgas parciales y la primera huelga general ferroviaria. Según los cálculos realizados por los funcionarios del Departamento Nacional del Trabajo, casi 67.000 obreros de todas las empresas ferroviarias se sumaron a la huelga general, de los cuales alrededor de 17.000 pertenecían a Vía y Obras y los telégrafos. ${ }^{54} \mathrm{Si}$ bien como resultado de la huelga el presidente Hipólito Yrigoyen dictó un reglamento de trabajo ferroviario en el que entre otras cuestiones se limitaba la duración de las jornadas laborales - que en el caso de los peones serían de 10 horas diarias o 60 semanales, de las cuales 8 horas diarias serían de trabajo efectivo y el resto para las comidas y para el traslado hacia el lugar de trabajo -, la discusión de un aumento de salarios quedó pendiente..$^{55}$ De todos modos, sí se había resuelto

50 Dos palabras a los trabajadores de Vía y Obras. La Confraternidad, Buenos Aires, p. 2, 15 dic. 1922.

51 Sección Rosario. El Obrero Ferroviario, Buenos Aires, p. 2, nov. 1912.

52 Huelgas. El Ferrocarril, Buenos Aires, p. 3, 1 nov. 1906.

53 Ibidem.

54 BDNT n. 42, 1919, p. 75.

55 El decreto de 11 de Octubre. La Fraternidad, Buenos Aires, p. 3, 15 sept. a 31 dic. 1917. 
autorizar una suba de jornales del $10 \%$ para los sueldos menores a $\$ 300$ mensuales, con el fin de que los mayores aumentos recayeran en los salarios más bajos. ${ }^{56}$

Mientras que el personal de Tracción, representado por La Fraternidad, comenzaba a negociar los escalafones con las empresas, durante 1918 el resto de los trabajadores ferroviarios se embarcaron en una serie de huelgas parciales en distintas compañías, cuyo fracaso reiterado generó malestar y desgaste entre las filas obreras. Algunas de estas huelgas fueron protagonizadas por peones de Vía y Obras que demandaban aumentos salariales y reducción de la jornada laboral, y en muchos casos contaron con el apoyo de trabajadores de otras reparticiones. En diciembre de 1919, los ferroviarios de la compañía de capitales británicos Central Córdoba se organizaron para presentar a la gerencia un pedido de escalafón que contemplara los salarios, ascensos, licencia anual, pagos por enfermedad y pases, entre otras demandas. Para los peones de cuadrilla se pedía un salario de $\$ 100$ a $\$ 110$ mensuales, y para los capataces un sueldo mensual de $\$ 160$. También se demandaba que el tiempo a emplearse entre la ida al lugar de trabajo y el regreso al punto de residencia se computara como trabajo efectivo dentro de las 8 horas establecidas en el reglamento de $1917 .{ }^{57} \mathrm{~A}$ pesar de que al comenzar 1920 los trabajadores de otras empresas, como el Central Argentino y el Sud, se sumaron al pedido de mejoras, en un contexto en el que la situación económica apremiaba con aumentos de los alquileres y de los artículos de consumo, las empresas y el gobierno no daban respuestas. ${ }^{58}$ Mientras tanto, el salario de los peones de diversas compañías oscilaba entre $\$ 1.60$ y un máximo de $\$ 3$ por día, de los cuales, en la mayoría de los casos, continuaba descontándose un porcentaje para la comida. ${ }^{59}$

Tras un par de meses sin respuestas de las empresas, algunas comenzaron a otorgar algunos aumentos, aunque, según informó un peón a fines de 1920, estos eran distribuidos de manera poco equitativa, beneficiando a aquellos que tenían sueldos más altos. ${ }^{60}$ En un caso, inclusive, un corresponsal de El Obrero Ferroviario denunció que los peones de cuadrilla del Ferrocarril Sud no sólo no habían recibido un aumento de salarios, sino que estos habían sido rebajados de $\$ 3$ diarios a $\$ 2.60 .61$ Poco antes de comenzar 1921, los trabajadores de los Sindicatos de Tráfico y Talleres - gremio sucesor de la FOF - confeccionaron escalafones para el personal de Tráfico, Talleres, y Vía y Obras, los cuales serían discutidos con representantes de las empresas y del Poder Ejecutivo. En relación a los trabajadores de las cuadrillas, el escalafón estipulaba jornadas de 8 horas diarias o un máximo de 48 horas semanales, y salarios mensuales que iban desde los $\$ 140$ a los $\$ 160$, en el caso de los peones, y de $\$ 190$ a \$220 para los capataces. Además de establecer las condiciones en que se efectuarían los

56 Nota de las empresas. El Obrero Ferroviario, Buenos Aires, p. 4, jul. 1918.

57 Reclamación del personal del Central Córdoba. El Obrero Ferroviario, Buenos Aires, p. 3, 1 ene. 1920.

58 Situación insostenible. El Obrero Ferroviario, Buenos Aires, p. 1, 16 ene. 1920; Torpe intransigencia. EI Obrero Ferroviario, Buenos Aires, p. 1, 1 feb. 1920.

59 BDNT n. 42, 1919, p. 237; Paraná. El Obrero Ferroviario, Buenos Aires, p. 4, 1 abril 1920.

60 Generosidad burguesa. El Obrero Ferroviario, Buenos Aires, p. 3, 16 nov. 1920.

61 Temperley. El Obrero Ferroviario, Buenos Aires, p. 4, 16 sep. 1920. 
ascensos y traslados, así como contemplar el otorgamiento de licencias, pases y viáticos entre otros beneficios -, para el caso de las cuadrillas de peones se establecía la abolición de la "olla" - es decir, la comida - que suministraban los capataces y se aclaraba que las empresas no podrían hacer descuentos de los jornales del personal en concepto de comidas. Respecto a la duración de la jornada laboral se especificaba que el tiempo que emplearan los peones en trasladarse desde el campamento al lugar de trabajo, y viceversa, debía ser computado como trabajo efectivo. ${ }^{62}$

En marzo de 1921, bajo control del gobierno nacional, se iniciaron las reuniones para discutir los escalafones entre representantes de las compañías y delegados del personal. Los primeros escalafones en discutirse y sancionarse fueron el de los guardas y el de los cambistas, a los que más tarde se agregaron el de los señaleros, el de auxiliares y dependientes de estación, y el de los telegrafistas. ${ }^{63}$ Sin embargo, en todos estos casos, no había sido posible llegar a un acuerdo en torno a los montos salariales, por lo que el asunto había quedado a estudio del gobierno. Al finalizar 1921, todavía estaba pendiente la fijación de los sueldos del personal comprendido en los escalafones sancionados, así como la elaboración de los escalafones del personal de Talleres y de Vía y Obras. Según denunciaron los trabajadores agremiados, si bien era cierto que en los últimos años habían tenido lugar algunos aumentos, éstos no llegaban a compensar el encarecimiento de los alimentos y otros artículos de consumo, ni tampoco alcanzaban al aumento salarial de los obreros de las industrias privadas en el mismo período de tiempo. Además, informaron que había ferroviarios, padres de familia muchos, que cobraban menos de $\$ 100$ mensuales y que la mayoría de los peones de cuadrilla ganaban todavía un promedio de $\$ 2.70$ por día, es decir, valores no muy superiores a aquellos presentes entre 1912 y $1914 .{ }^{64}$

\section{La vida en el campamento}

POR LAS PROPIAS CARACTERÍSTICAS de las tareas que realizaban los obreros de las cuadrillas, trabajando en distintas secciones de las líneas, generalmente en zonas remotas y aisladas, gran parte de su vida transcurría en los campamentos, puntos de residencia transitorios e itinerantes desde los que se desplazaban al lugar en el que fuera necesario realizar su trabajo. En este apartado el análisis se centra en la vida cotidiana en los campamentos buscando recuperar las vivencias de los propios peones, preguntándose por cómo sus experiencias laborales, sus trayectorias migrantes, la convivencia diaria y las jerarquías existentes en el

62 Escalafón del Personal de Talleres, Vías y Obras. El Obrero Ferroviario, Buenos Aires, p. 1, 16 dic. 1920.

63 Materializando nuestras aspiraciones. El Obrero Ferroviario, Buenos Aires, p. 1, 1 abril 1921; Discusión de los escalafones. El Obrero Ferroviario, Buenos Aires, p. 2, 1 mayo 1921; Escalafón de los auxiliares y dependientes de Estación. El Obrero Ferroviario, Buenos Aires, p. 3, 16 jul. 1921; Escalafón de señaleros. El Obrero Ferroviario, Buenos Aires, p. 1, 16 ago. 1921; Escalafón de telegrafistas. El Obrero Ferroviario, Buenos Aires, p. 1, 1 nov. 1921.

64 La amenaza. El Obrero Ferroviario, Buenos Aires, p. 1, 1 nov. 1921. 
interior de las cuadrillas se entramaron en sus prácticas, expectativas, y sentidos sobre su trabajo.

Si bien en algunos casos, las empresas disponían de vagones que servían de dormitorio para los peones y otros trabajadores, lo más común fue que los hombres que integraban las cuadrillas levantaran su vivienda en carpas facilitadas por las compañías, las cuales se ubicaban cerca del lugar de trabajo y en las que se alojaban entre cinco y seis hombres. El "mobiliario", en cambio, era propiedad de los peones que las ocupaban y podía estar compuesto por un colchón, ropa de cama, algunas herramientas y elementos de cocina. ${ }^{65}$ Tal como puede apreciarse en una de las imágenes (foto 1) que acompañaba la crónica publicada en la revista PBT a fines de 1912, y que en conjunto permiten hacerse una idea de la vida material de los peones en el trabajo y los campamentos, las carpas se encontraban dispuestas sobre la tierra, una al lado de otra, formando una hilera. Delante de ellas había mesas y bancos alargados de madera que probablemente eran usados al momento de las comidas, constituyendo asimismo una zona de reunión en donde los peones podían sentarse en grupo y conversar. También se ve una especie de tinglado precario, quizás la zona en donde se preparaba la comida para protegerla de posibles lluvias.

\section{Foto 1 - "Las carpas de los obreros del riel, durante un descanso al mediodía".}

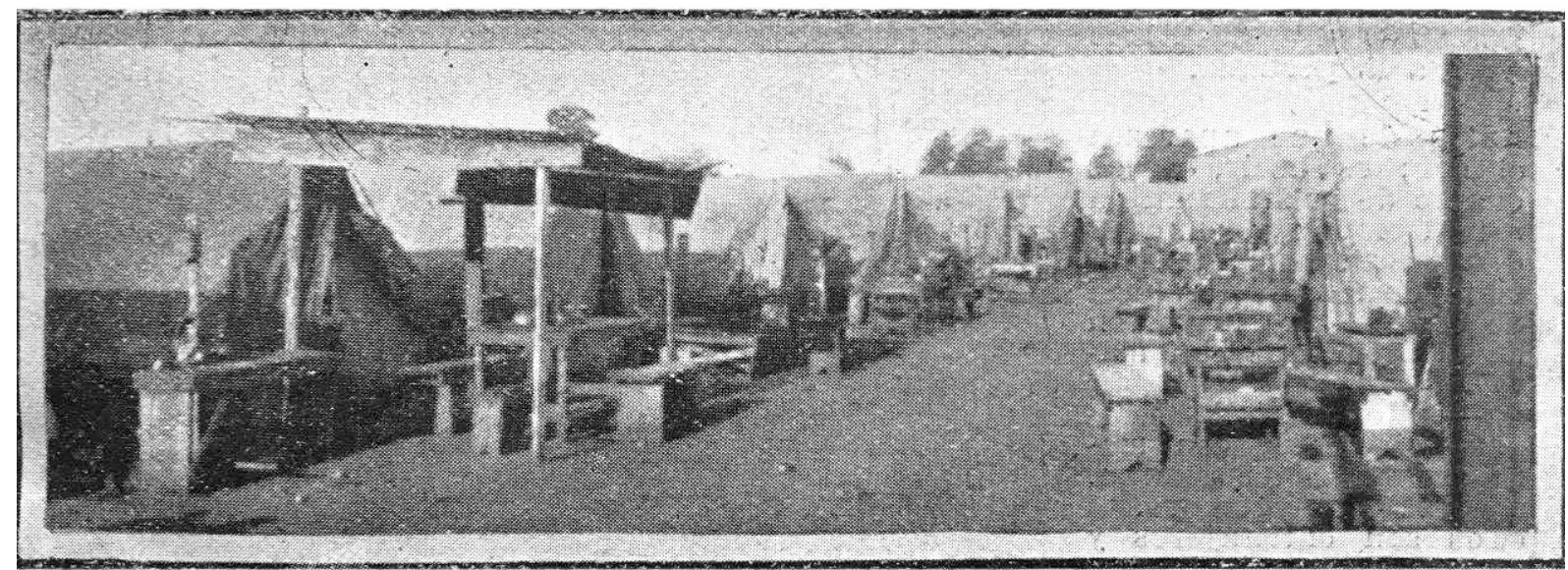

Fuente: PBT, Buenos Aires, 21 dic. 1912.

Sobre la rutina de los peones - en su mayoría extranjeros, principalmente italianos -, según informó al cronista de PBT un capataz de cuadrilla del Ferrocarril Oeste, éstos se levantaban a las 4 de la mañana para empezar a trabajar y tres horas después tenían media hora de reposo en la que aprovechaban para desayunar, generalmente, mate cocido. A las 11 volvían a cortar las tareas para almorzar junto al campamento, en donde estaba instalada la cocina, y una hora y media más tarde regresaban al trabajo, el cual se extendía hasta la puesta del

65 FERROCARRIL BUENOS AIRES AL PACÍFICO. Legajo personal, Amato Pablo. Archivo General del Ferrocarril, Buenos Aires-Argentina. Fondo Recursos Humanos Ferroviarios. En 1871, a pocos meses de haber llegado a Argentina, el español Luis Aldaz consiguió trabajo como peón ferroviario. Según le contó a su esposa en una carta, con el primer pago había comprado un colchón y un catre, entre otras cosas de primera necesidad (citado en BJERG, op. cit., p. 67). 
sol. Por la noche solían irse a dormir temprano, aunque algunas veces, sobre todo cuando el tiempo estaba lindo, se sentaban a la entrada de las carpas y, quizás acompañados por alguna bebida alcohólica como vino, cerveza o caña, pasaban un rato de diversión cantando, tocando algún instrumento como el acordeón o la guitarra, o jugando a las cartas. ${ }^{66}$ Estas actividades compartidas dan cuenta de los momentos de sociabilidad, complicidad y camaradería que podían forjarse durante la convivencia en los campamentos y que podían hacer que las duras condiciones de trabajo resultaran, al menos, un poco más llevaderas.

Las cuadrillas acostumbraban a trasladarse de lugar en lugar a pie o en zorras, junto con la cocina ambulante, los equipos para servir la comida y las herramientas de trabajo. Los hombres que conformaban la peonada permanecían así gran parte del tiempo alejados de sus moradas y conviviendo entre ellos. Realizaban un trabajo a la intemperie, con tareas que implicaban fuerza y destreza física. En general, se trabajaba todo el año, de sol a sol, aunque existían momentos de descanso y los domingos era el día libre, salvo en casos especiales o por órdenes superiores. Ese día de descanso era aquel en el que los peones solían limpiar sus ropas y su catre, armar su ajuar, afeitarse y cocinar en fogones alguna comida para reemplazar al puchero reglamentario que, como se ha visto más arriba, generaba todo tipo de disconformidades y protestas. ${ }^{67}$

\section{Foto 2 - "Bachichín repartiendo el puchero a la peonada".}

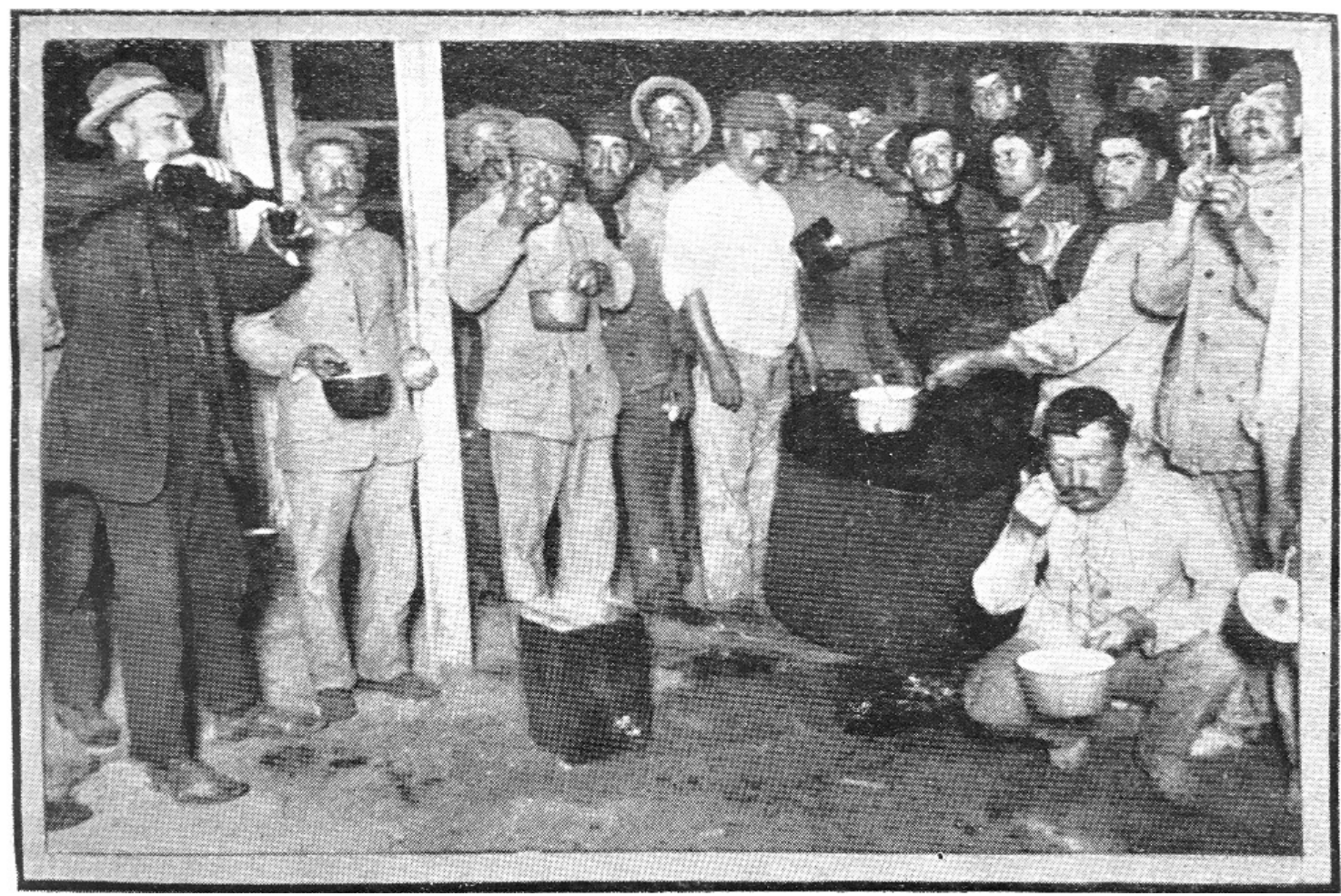

Fuente: PBT, Buenos Aires, 21 dic. 1912.

66 El obrero del riel. PBT, Buenos Aires, 21 dic. 1912.

67 Los peones de la vía. Revista Mensual del F.C.C.A., Buenos Aires, p. 49, jun. 1918. 
En la foto 2, también parte de la crónica publicada en PBT, se ve a un grupo de peones comiendo un puchero tras la jornada de trabajo. Alrededor de una gran olla apoyada en el suelo de tierra se concentra la mayor parte del grupo. Parece una imagen bastante espontánea de lo que era una comida y un momento de comensalidad en el campamento. A diferencia de otras fotografías de trabajadores ferroviarios de la época, correspondientes al personal de trenes o de estaciones, aquí no se ve orden ni prolijidad en la distribución del grupo ni en su aspecto, ni tampoco parece haber jerarquías entre los obreros. Las ropas de los peones - chaquetas, camisas, sacos, pantalones, boinas y sombreros de distintos colores - parecen desgastadas, arrugadas y sucias, comen parados y cada uno de su propia olla. Aunque la mayoría mira a cámara y posa para la foto, otros parecen inadvertidos de la lente y continúan concentrados en sus platos o sirviendo bebida en un vaso. Uno es el encargado de repartir el puchero y mira a cámara con cierta complicidad mientras realiza su tarea. A juzgar por el epígrafe de la imagen, se trata de un "bachinchín", término genovés que, si bien era el diminutivo del nombre Juan Bautista, en la Argentina de comienzos del siglo XX se utilizaba para designar a los italianos "pobres y buenos". 68

Distintas evidencias apuntan al origen extranjero de los peones, en su mayoría italianos, algunos "con penas de amor" o "angustias de paternidad", según afirmó a mediados de 1918 la revista del Central Argentino, al dar cuenta de que muchos peones se encontraban alejados de sus esposas e hijos, los que cada mes enviaban "sus baccios juguetones per il mio caro papá" ${ }^{69}$ Sin dudas, muchos peones compartían no sólo la experiencia del trabajo, sino también de la migración. De acuerdo al autor de la nota con tintes literarios publicada en la revista empresarial, detrás de la imagen de hombres rudos que proyectaban estos obreros se escondían tragedias, romances, recuerdos de una tierra lejana y un hogar ausente, memorias y añoranzas de su patria y sus años mozos. Para indagar sobre estos aspectos, resultan especialmente interesantes las libretas del italiano Geniale Giretti, un obrero que entre 1905 y 1907 estuvo en Bahía Blanca e Ingeniero White - al sur de la Provincia de Buenos Aires - trabajando en el ferrocarril como peón de cuadrilla, pero también en la cosecha y como sereno y albañil. A partir de sus anotaciones personales es posible acceder a la experiencia del trabajo en las vías en primera persona, así como reconstruir algunos trazos de su trayectoria migrante, su experiencia laboral, su vida familiar, sus reflexiones y preocupaciones.

68 MEO ZILIO, Giovanni. Genovesismos en el español rioplatense. Nueva Revista de Filología Hispánica, $\mathrm{n}$. 3-4, p. 245-263, 1964.

69 Los peones de la vía. Revista Mensual del F.C.C.A., Buenos Aires, p. 49, jun. 1918. Si bien la mayoría de los extranjeros que trabajaban como peones de cuadrilla eran italianos, a principios de 1912 el Ferrocarril Central Argentino intentó darle trabajo a una cuadrilla de sesenta indios que habían llegado al país en enero desde Punjaub y que fueron mandados a un entrenador en San Martín, en las afueras de Buenos Aires. Allí, estuvieron cuatro días trabajando cuando la mitad de la cuadrilla consideró que la paga diaria de $\$ 2,50$ era muy poca y por eso decidieron buscar otro trabajo. El ingeniero de sección, autor de la nota, afirmaba que darle de comer a la cuadrilla había sido más caro que a una cuadrilla italiana (70 centavos por día contra 55) y que, habiendo pasado la novedad de tener indios para trabajar en la sección, era claro que en la Argentina estos jamás podrían competir con italianos, españoles o turcos. East Indians in Argentina. Central Argentine Railway Magazine, Buenos Aires, p. 138, mar. 1912. 
Durante sus años en la Argentina, Giretti escribió una especie de diario íntimo en el que registró su día a día, atendiendo a cuestiones como sus desplazamientos de un lugar a otro, los trabajos que iba consiguiendo, la relación con jefes, paisanos y compañeros de trabajo, sus ingresos y gastos. También dejó escritos dos poemas y un relato en tono novelado sobre su vida y su paso por América del Sur. A diferencia de lo que sucede con las autobiografías o memorias escritas por trabajadores, en general por aquellos que se destacaron por su actividad sindical y política, el diario escrito por Geniale Giretti no fue concebido para ser leído por otros ni para ser publicado, y en este sentido permite acercarse de otro modo a su subjetividad, sentimientos y percepciones. A la vez, sus notas fueron escritas al mismo tiempo en que sucedían los hechos de los que dejó constancia, por ende, no estuvieron mediadas por un largo lapso de tiempo ni reconstruidas a partir de recuerdos lejanos, constituyendo un registro más inmediato y menos elaborado sobre su experiencia.

Siguiendo su propio relato de vida, nacido "humilde y pobre campesino", desde chico Geniale Giretti había sentido deseos de aprender e instruirse. ${ }^{70}$ A los 5 años recibió de su padre las primeras lecciones de lectura y escritura, pero como este no sabía tanto, decidió mandarlo con un cura, a quien más tarde Giretti dejó para ir a la escuela comunal. Mientras trabajaba como campesino, Giretti conoció a un ingeniero instruido que le tomó afecto y le enseñó cosas nuevas. Gracias a los conocimientos adquiridos, a los 17 años comenzó a trabajar como maestro de un grupo de niños a quienes les enseñaba a leer y escribir la lengua italiana recibiendo un pequeño pago a cambio. Tres años más tarde, en abril de 1902, se casó con Concetta Mazzarini y dos años después la mujer dio a luz a la primera hija de ambos, Leticia. Mientras tanto, Giretti trabajaba la tierra de un patrón y continuaba dando clases, lo que le permitía llevar una vida tranquila junto a su mujer y su hija, y ganar lo necesario para pequeños gastos. Tras un desentendimiento con su patrón, que lo echó de su tierra, Giretti se decidió a buscar suerte en América, idea que desde hacía tiempo rondaba en su cabeza. El hecho de que su esposa se encontrara embarazada quizás jugó un rol central en su iniciativa de migrar en busca de un mejor porvenir. Tal vez su idea era juntar dinero y regresar pronto a su tierra natal o acaso conseguir la estabilidad que le permitiera llamar a su mujer y sus hijos para que se instalaran con él en el nuevo país. Con 23 años, el 24 de octubre de 1905, Geniale Giretti se despidió de su madre, de su esposa y de su pequeña hija, y junto con su padre partió desde su pueblo, San Vittore, en la región italiana de Le Marche, hacia el puerto de Génova desde donde el 27 de octubre salió el barco que lo llevaría a Argentina.

Al llegar al puerto de Buenos Aires, lo primero que hizo Giretti fue sacar boletos de tren para ir a Torquinst, localidad en el sudoeste de la provincia de Buenos Aires a la que arribó el 21 de noviembre. Allí se encontró con un primo suyo que lo llevó a él y a su padre a trabajar con un chacarero italiano, ${ }^{71}$ lo que sugiere que Giretti tenía algún contacto e información que

70 Las libretas de Geniale Giretti, 1905-1907. Bahía Blanca: Ferrowhite, 2008.

71 En general, los chacareros eran arrendatarios que a su vez subcontrataban peones para cultivar la tierra. Como señala Fernando Devoto en su estudio sobre la inmigración en la Argentina, muchos de los trabajadores 
seguramente había recopilado antes de emprender su viaje. Para la mayoría de los recién llegados, resultaba fundamental contar con la ayuda de parientes, amigos o conocidos, a través de los cuales podían acceder a oportunidades de empleo, transporte y localización en la sociedad de destino. Si bien disponer de estas redes implicaba cierta seguridad para el inmigrante recién llegado, lo cierto es que siempre podían suceder infortunios que alteraran los planes. Así fue que habiendo pasado menos de un mes de su arribo, Giretti sufrió un accidente al caerse de un caballo, lo que le generó una gran molestia y dolor en su brazo derecho que lo dejó imposibilitado para trabajar en la cosecha de trigo, con la que esperaba ganar un buen dinero.

Luego de trasladarse por distintos pueblos de la zona y conseguir, nuevamente gracias a conocidos, trabajos temporarios como sereno y como albañil, a mediados de 1906 Giretti comenzó a trabajar como peón ferroviario junto con su padre en la línea Bahía Blanca al Noroeste, perteneciente al ferrocarril de capitales británicos Buenos Aires al Pacífico. Al poco tiempo su padre enfermó gravemente, lo que según el relato de Giretti se relacionaba con su edad avanzada y la precariedad de su vida material como peones que dormían "en una carpa, verano e invierno, donde el viento sopla y la lluvia pasa". ${ }^{72}$ Tras interrumpir su trabajo para atender y cuidar a su padre, Giretti volvió a trabajar a la cuadrilla, pero luego de seis jornadas, el 7 de agosto, al encontrarse apretando un tornillo, comenzó a sentir un dolor muy fuerte en su pulgar derecho que le impidió ir a trabajar a la mañana siguiente, motivo por el cual el capataz decidió echarlo. Si bien Giretti viajó a la ciudad de Bahía Blanca para hacerse acomodar el brazo una vez más, ya que desde el accidente con el caballo las molestias eran periódicas, el dolor persistió, dificultándole realizar correctamente el trabajo como peón que había conseguido en Bahía y del cual fue despedido tras dos días de labor. Sin duda, el cuerpo constituía la principal herramienta de los trabajadores y un accidente, enfermedad o dolencia podían afectar el desempeño laboral y costarles el puesto de trabajo.

Luego de comprarle un pasaje al padre para que pudiera volver a Italia y acompañarlo hasta Buenos Aires para tomar el barco, Giretti regresó a Bahía Blanca y a fines de agosto de 1906 se unió a una cuadrilla de peones ferroviarios en el pueblo de Saavedra, a poco más de 100 kilómetros de la ciudad. Luego de dejar esa cuadrilla porque el trabajo le resultaba demasiado pesado, Giretti se unió a otra cuadrilla con la que estuvo trabajando en distintos pueblos de la zona, interrumpiendo su labor como peón para ir a la cosecha y luego reincorporándose al trabajo en las vías. Esta intermitencia laboral era común entre los peones, quienes en muchos casos realizaban un trabajo temporal en el ferrocarril - ingresando y saliendo voluntariamente de las cuadrillas - que combinaban con el trabajo en la cosecha o la construcción. En sus notas de aquel entonces - escritas en "cocoliche", una mezcla de

extranjeros que se ocuparon en las cosechas encontraban una rápida disponibilidad de trabajo, no tanto por la relación entre oferta y demanda, sino por la mayor confianza que los propietarios o arrendatarios "gringos" tenían hacia los trabajadores de su mismo grupo nacional o regional. DEVOTO, Fernando. Historia de la inmigración en la Argentina. Buenos Aires: Sudamericana, 2009. p. 75.

72 Las libretas de Geniale Giretti. 1905-1907, op. cit., p. 84. 
su italiano natal y el castellano que estaba comenzando a aprender - Giretti dejó constancia de su rutina y cotidianeidad en el campamento, registrando de manera sucinta no tanto sus tareas laborales sino cuestiones más bien relacionadas con su vida material y el trato y la convivencia con sus compañeros de trabajo. Entre otras cosas, dejó asentadas las lluvias y otros fenómenos climáticos como el granizo, la neblina o el viento - que incidían de forma especial en el trabajo de las cuadrillas -, el dinero que cobraba, sus consumos y gastos, las mudanzas del campamento - con los consiguientes viajes de un lugar a otro - y el intercambio de correspondencia con su madre, su padre y su mujer. También, registró sus malestares físicos - fiebre, resfrío, dolores de cabeza, de ojos, de panza, de un brazo o una pierna - y algunos accidentes con la manipulación de las herramientas de trabajo, los que podían dejarle un dedo machucado o un golpe en un ojo.

La jornada laboral comenzaba temprano y a veces con mate que el mismo Giretti preparaba, mientras que la comida, como ya se ha visto, corría por cuenta del capataz. La convivencia diaria en el campamento podía acarrear problemas y en varias oportunidades Giretti registró desentendimientos con el capataz, así como con compañeros de trabajo y de carpa, quienes, a juzgar por los nombres, en su mayoría eran italianos como él. En una ocasión, por ejemplo, se enojó con el peón Berdini Achille por haberle perdido un cuchillo seguramente parte de las herramientas personales del propio Giretti - y en otra oportunidad discutió con uno de sus compañeros de carpa, Salvatore Abruzzese, porque este no quería orinar fuera de la carpa, motivo por el cual decidió mudarse a otra tienda. ${ }^{73}$ Por otra parte, no cumplir con las exigencias del trabajo podía implicar desentendimientos con la superioridad, como le sucedió a Giretti una mañana en que no logró a levantarse a tiempo y llegó unos minutos tarde a su puesto de trabajo, por lo cual el capataz quiso descontarle parte de su jornal, hecho que hizo enojar al peón italiano, quien decidió dejar el campamento para ir a trabajar a otra cuadrilla. ${ }^{74}$

Una vez por mes, se presentaba el pagador en el campamento y realizaba el pago a los peones. En el tiempo durante el cual Giretti llevó su libreta, nunca registró un salario mayor a $\$ 55$, habiendo meses en los que cobró $\$ 47$, otros $\$ 38$, y otros en los que percibió poco más de $\$ 23$, lo que seguramente obedeció a la intermitencia de su trabajo como peón. Parte de este dinero era enviado a Italia, dirigido a su madre o a su padre, quienes quizás eran los encargados de suministrar dinero a su esposa, y el resto estaba destinado a sus gastos personales. Tabaco, fósforos, café, azúcar, naranjas, melones, sardinas, vino, cerveza, caña, calzoncillos, jabón, billetes de lotería, rifas, estampillas, fueron algunos de los consumos registrados en su libreta. De acuerdo a sus anotaciones, los domingos era el día en que Giretti se ocupaba de cuestiones personales, tales como cortarse el cabello y/o la barba, limpiar sus ropas, comprar tabaco o un par de alpargatas.

73 Ibídem, p. 15 y 22.

74 Ibídem, p. 103. 
En suma, en el relato de Geniale Giretti sobre sus años en Argentina se vislumbran algunos de sus sentimientos y preocupaciones en relación al trabajo y la familia, los cuales permiten apreciar que la migración podía sacar a la luz emociones negativas relacionadas con la frustración de la expectativa de progreso económico que perseguían quienes migraban. ${ }^{75} \mathrm{~A}$ diferencia de las imágenes más difundidas sobre la experiencia de la migración, la de Giretti no es una historia lineal, ni necesariamente exitosa, ni de ascenso social. Poco después de terminar de escribir el relato novelado sobre su vida, a fines de 1907 o comienzos de 1908, Geniale volvió a Italia. ${ }^{76}$ No es posible saber si retornar a su país siempre estuvo entre sus planes y su migración fue concebida como algo estacional, o si volver fue una decisión tomada en Argentina a partir de las experiencias allí vividas. ${ }^{77}$ Puesto que Giretti viajó a la Argentina en dos oportunidades más, es probable que fuera un migrante estacional, uno de los tantos inmigrantes "golondrina" que llegaban al país para trabajar de manera temporal, generalmente en actividades ligadas con las cosechas. De hecho, su llegada a la Argentina en 1905 coincidió con la fecha en la que comenzaban las cosechas, en los meses de verano, y él mismo dejó escrito que su intención era hacer la cosecha de trigo.

\section{Conclusión}

En LA ARgentina de comienzos del siglo XX la red ferroviaria se encontraba en plena expansión: se inauguraban nuevas líneas, otras se extendían, se construían depósitos de locomotoras y talleres de reparación y mantenimiento del material rodante, algunos de los ya existentes se ampliaban, crecían las obras, y con todo ello aumentaba el número de trabajadores empleados en los ferrocarriles. Ahora bien, este auge ferroviario, el crecimiento y prosperidad que vivieron las empresas - mayormente en manos de capitales extranjeros, principalmente británicos -, no se tradujo en bonanza para sus trabajadores, e incluso la situación vivida por los peones de Vía y Obras contrastaba notablemente con la de otros obreros de las mismas compañías.

Detenerse en el mundo laboral en las vías férreas pone en evidencia una realidad soslayada por los estudios que se han ocupado de analizar el trabajo en los ferrocarriles en la Argentina de comienzos del siglo XX. Al examinar las experiencias y condiciones laborales de los peones, algunos de sus reclamos, demandas y luchas, así como la cotidianeidad de la vida en el campamento, ha sido posible dar cuenta de la precariedad de las condiciones de trabajo de este sector y echar luz sobre la diversidad de situaciones y heterogeneidad laboral existente en los ferrocarriles. En particular, tomar el caso de las cuadrillas de Vía y Obras, reconstruir sus tareas y labores, sus espacios de trabajo, las

75 BJERG, María. Matrimonios malogrados y pasiones iracundas: inmigrantes en la justicia criminal. Ciudad de Buenos Aires, 1900-1920. Revista Historia y Justicia, n. 11, p. 42-67, oct. 2018.

76 Las libretas de Geniale Giretti. 1905-1907. Op. cit., p. 12.

77 Así como algunos inmigrantes se quedaban, otros retornaban a sus países de origen y ello no necesariamente implicaba un "fracaso". Entre 1861 y 1920 retornaron a su país un poco más de la mitad de los inmigrantes italianos llegados a la Argentina. DEVOTO, op. cit., p. 73. 
calificaciones y jerarquías existentes en su interior y en relación a otros trabajadores del ferrocarril, permitió identificar dimensiones de la experiencia de trabajo que se distancian significativamente de ciertas interpretaciones que han entendido a los ferroviarios como un sector laboral privilegiado. Salarios relativamente elevados, beneficios extra salariales, estabilidad laboral, o la posibilidad de hacer carrera - condiciones que habrían definido a estos trabajadores como una "aristocracia" o "elite obrera"78 - no estaban presentes entre los peones encargados de la reparación y mantenimiento del material rodante y las vías. Alumbrar sobre la precariedad laboral de los trabajadores de Vía y Obras invita a repensar, matizar y complejizar esta interpretación, a la vez que posibilita abordar el mundo del trabajo en los ferrocarriles desde nuevas y enriquecedoras perspectivas.

Recebido em: 28/07/2020

Aprovado em: $24 / 08 / 2020$ 